\title{
Meaning change and retroactive effects following low meaningful stimulus and response satiation'
}

\author{
R. KANUNGO AND LYNN ROSS \\ DALHOUSIE UNIVERSITY, HALIFAX
}

Retroactive effects of satiation treatment were studied using nonsense verbal items. Response recall was facilitated by interpolated response satiation but was not affectedby stimulus satiation. Some evidence for an interaction of instructions with regression effect was noticed in the case of $\mathrm{Ss}^{\prime}$ semantic ratings.

An associational interpretation of semantic satiation assumes that continued repetition of a word results in extinction of its old meaning response and in the formation of a new word-word habit. Thus it is argued (Kanungo \& Lambert, 1963) that satiation treatment to a nonsense verbal item should result in only a wordword habit without any meaning change, the effect of which can be studied in paired associate learning.

The present study is designed to verify Kanungo \& Lambert's (1963) contention that satiation treatment to nonsense items do not result in significant semantic change; and to test the predictions of Kanungo, Lambert, \& Mauer (1962), that by using low meaningful S-R pairs one can obtain retroactive facilitation and inhibition effects respectively after interpolated satiation treatment to the response and stimulus items.

Method

Twelve low meaningful paralogs (Noble, 1952) were used to prepare a list of six paired-associates. The meaningfulness $(\mathrm{m})$ of stimulus and response members were equated. Another six paralogs matched for their $\underline{m}$ with the six stimulus or six response items of the P-A list were chosen as control items. Three semantic differential scales were used (good-bad, active-passive, strong-weak).

All 48 Ss were asked to learn the P-A list by the anticipation method on a memory drum at a 2:2 rate with $4 \mathrm{sec}$. intertrial intervals. Five different orders of the pairs in the list were used to minimise the effects of serial learning. All Ss learned the list to a criterion of one perfect recall. On the basis of the total number of trials and errors to criterion, Ss were divided into four matched groups of $12 \mathrm{Ss}$ in each.

After learning the P-A list, one group got satiation treatment to the stimulus items (SS), another group got satiation treatment to the response items (RS) and a third group got similar treatment to the control items (CS). The fourth group did not get any satiation treatment (NS), but during an equivalent period was engaged in reading a passage. The satiation procedure for SS, RS, and CS groups was similar to that of Kanungo \& Lambert (1963) study. For any one S, the semantic profile was taken for all six items (stimulus, or response or control items as the case may be) on the three scales. Then the $S$ continuously repeated an item at a rate of 2-3 repetitions per second for a period of $15 \mathrm{sec}$., immediately after which he gave his rating for the item on a scale. The procedure was repeated three times for each of six items, once for each semantic scale. The order of presentation was randomised to maximise the separation of the reoccurrence of each word and each scale.

After the interpolated treatment, all Ss were shown each stimulus item in the P-A list for $2 \mathrm{sec}$. and asked to recall the response item paired with it.

\section{Results and Discussion}

Two way analysis of variance with repeated measures was performed on the polarity ratings of the three groups who were measured both before and after satiation treatment. Only one main effect, differences in pre- and post-satiation ratings were significant $(\mathrm{F}=17.8, \mathrm{df}=1 / 33, \mathrm{p}<.01)$. The mean polarity ratings as presented in Table 1 decreased after satiation treatment. The interaction effect, which was also significant at the .01 level $(F=17.8 ; d f=1 / 33)$, suggests that satiation treatment differentially affected the three groups. The mean polarity scores (see Table 1) show that in the present study there is a relatively intense pre-satiation rating and a greater decrease in the mean rating of the SS group following satiation treatment than the other two groups. These results certainly do not agree with the earlier findings of Kanungo \& Lambert (1963) even though both studies used similar materials and procedure. To account for the differences, comparable data from the earlier study (Kanungo \& Lambert, 1963) was obtained. These are also presented in Table 1. For each of the three groups the pre-satiation ratings of the present study is much more intense than those of the earlier study. Besides, while nonsignificant differences between pre-and post-satiation ratings were observed in the earlier study (Kanungo \& Lambert, 1963), a significant decrease in ratings following satiation is observed in the present study. This observation and the significant interaction effect found in the present study point to some kind of regression effect (Yelen \& Schulz, 1963). That is, if the pre-satiation rating of a

Table 1. Pre- and Post-Satiation mean semantic ratings over the sum of three scales

\begin{tabular}{llll} 
Earlier Study & \multicolumn{2}{c}{ Present } & Study \\
Pre & Post & Pre & Post \\
2.45 & 2.77 & 5.43 & 5.22 \\
1.92 & 1.90 & 6.08 & 5.44 \\
0.35 & 0.33 & 5.29 & 4.93
\end{tabular}


paralog is relatively intense, the post-satiation rating tends to be less intense. But why was the presatiation ratings of paralogs less intense in the study by Kanungo \& Lambert (1963), whereas in the present study they were more intense? The answer seems to lie in the subtle differences between the two studies with respect to E's instruction to Ss. In the earlier study, while being given instructions for satiation treatment, the Ss were given a few practice items including both highly meaningful words and nonsense paralogs to rate on semantic differential scales. In the present study, however, the practice items did not include any meaningful word and the Ss were asked to rate only paralogs on the three meaning dimensions. Thus, the inclusion of meaningful words as examples in the earlier study might have introduced a set in Ss to rate paralogs always as more neutral and, therefore, less intense as compared to the ratings of Ss in the present study. This contextual effect also explains why in the earlier study a regression effect (meaning generation) was not observed. It seems that occurrence of the regression effect is partly a function of S's set induced by instructions at the time of rating.

Analysis of the recall data revealed that 26 out of 48 Ss showed perfect recall. Thus, within each group, the Ss were categorized into those who committed some error (ranging from 1 to 3 ) exhibiting presence of retroactive inhibition (RI) and those who had perfect recall exhibiting absence of any $\mathrm{RI}$. The difference among the four groups in terms of the distribution of Ss showing RI, as presented in Fig. 1, is significant $\left(\mathrm{X}^{2}=8.39, \mathrm{df}=3, \mathrm{p}<.05\right)$. Comparison of two groups at a time reveals that $\mathrm{RS}$ differs significantly from CS at the .02 level $\left(X^{2}=6.04, d f=1\right)$. Other comparisons showed non-significant differences. Note that comparison of SS or RS with CS as a control is more meaningful than comparing the former with NS group. This is because NS group lacks an interpolated verbal repetition that the other three groups have.

These results support the prediction that retroactive facilitation results from interpolated satiation treatment to low meaningful response items, but they failed to

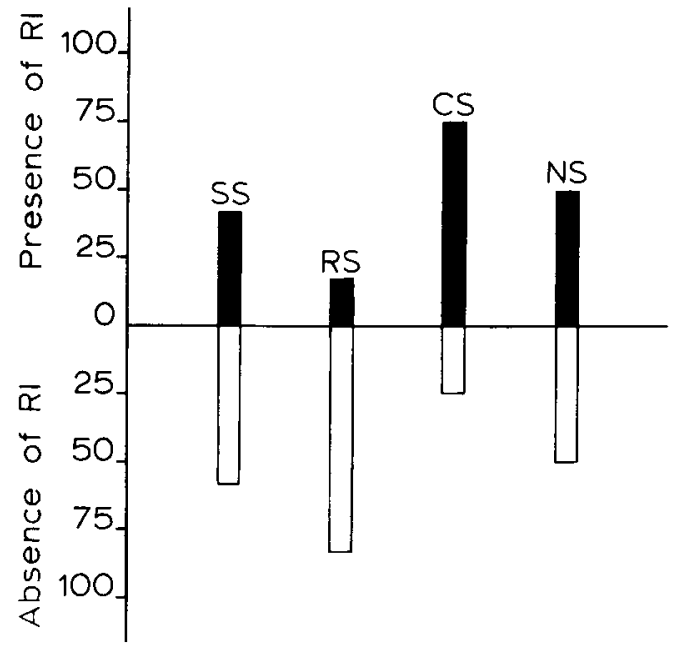

Fig. 1. Percentage of Ss showing either presence or absence of RI under different conditions.

demonstrate interference effects of stimulus satiation. The reason for such failure could be that the items used in the study were quite unfamiliar and satiation treatment increased their familiarity for the S. Thus when stimuli are satiated, the retroactive interference effect via the word-word habit is presumably counteracted by the facilitatory effects of stimulus familiarity.

\section{References}

Kanungo, R., \& Lambert, W. E. Paired associate learning as a function of stimulus and response satiation. Brit. J. Psychol., $1963,54,135-144$.

Kanungo, R., Lambert, W. E., \& Mauer, S. M. Semantic satiation and paired-associate learning. J. exp. Psychol., 1962, 64, 600-607.

Noble, C. E. An analysis of meaning. Psychol. Rev., 1952, 59, 421-430.

Yelen, D. R., \& Schulz, R. W. Verbal satiation? J. verbal Learn. verbal Behav., 1963, 1, 372-377.

\section{Note}

1. The study was supported partly by Grant No. $9401-22$ from the Defence Research Board of Canada and partly by Grant No. X-8480 from Dalhousie University Research Development Fund. 